\title{
The Role of Nitric Oxide Synthase in Cortical Plasticity Is Sex Specific
}

\author{
James Dachtler, ${ }^{\star}$ Neil R. Hardingham, ${ }^{\star}$ and Kevin Fox \\ Cardiff School of Biosciences, Cardiff University, Cardiff CF10 3AX, United Kingdom
}

Nitric oxide synthase-1 (NOS1) is involved in several forms of plasticity including hippocampal-dependent learning and memory, experience-dependent plasticity in the barrel cortex, and long-term potentiation (LTP) in the hippocampus and neocortex. NOS1 also contributes to ischemic damage during stroke and has a stronger deleterious effect in males than females. We therefore investigated whether the role of NOS1 in plasticity might also be sex specific. We tested LTP in the layer IV-II/III pathway between barrel columns and experience-dependent plasticity in the barrel cortex of $\alpha$ NOS1 knock-out mice and their wild-type littermates. We found that LTP was absent in male $\alpha$ NOS1 knock-out mice but not in females and that the residual LTP in females was not NO dependent. We also found that experience-dependent potentiation due to single whisker experience was significantly reduced in male $\alpha$ NOS1 knockouts but was unaffected in females. The $\alpha$ NOS1 knockout had a small effect on the development of the barrels, which were reduced in size by $20 \%$ compared with wild types, but this effect was not sex specific. We therefore conclude that neocortical plasticity mechanisms differ between males and females at the synaptic level, either in their basic plasticity induction pathways or in their ability to compensate for loss of $\alpha$ NOS1.

\section{Introduction}

Synaptic plasticity is thought to underlie a number of important functions in the brain, including learning, memory, and development of neural circuits (Constantine-Paton et al., 1990; Bliss and Collingridge, 1993). However, many of the factors involved in long-term potentiation (LTP) when dysregulated during stroke or epilepsy are linked to excitotoxic injury, including NMDA receptors (Herron et al., 1986; Olney et al., 1987), calcium (Lynch et al., 1983; Bano and Nicotera, 2007), and CaMKII (Malinow et al., 1988; Hajimohammadreza et al., 1995). One further factor thought to be a major mediator of excitotoxic injury is nitric oxide (NO) (Huang et al., 1994; Dawson et al., 1996): similarly, this molecule plays an important role in LTP in the hippocampus and neocortex (Schuman and Madison, 1991; Hardingham and Fox, 2006).

$\mathrm{NO}$ is produced by the enzyme NO synthase (NOS). Studies have identified one of the isoforms, NOS type 1 (NOS1), as a factor involved in stroke susceptibility and generation of ischemic damage in stroke (Huang et al., 1994; Nanri et al., 1998; Manso et al., 2012). More specifically, $\alpha$ NOS1 appears to be the subisoform involved, because inhibiting the association of NOS with PSD-95 is protective for stroke (Cao et al., 2005). The

Received July 3, 2012; revised Aug. 13, 2012; accepted Aug. $27,2012$.

Author contributions: J.D. and N.R.H. designed research; J.D. and N.R.H. performed research; J.D., N.R.H., and K.F. analyzed data; J.D., N.R.H., and K.F. wrote the paper.

This research was funded by the Medical Research Council (United Kingdom) and the National Institute of Mental Health NIMH (Conte Centre).

*J.D. and N.R.H. contributed equally to this work.

The authors declare there are no competing financial interests.

Correspondence should be addressed to Prof. Kevin Fox, Cardiff School of Biosciences, Cardiff University, Cardiff CF103AX, United Kingdom. E-mail: Foxkd@cardiff.ac.uk.

DOI:10.1523/JNEUROSCI.3189-12.2012

Copyright $\odot 2012$ the authors $\quad 0270-6474 / 12 / 3214994-06 \$ 15.00 / 0$ $\alpha$ NOS1 isoform has also been shown to be important for experience-dependent potentiation (EDP) and LTP in the barrel cortex (Dachtler et al., 2011b).

Regulation of NO is known to differ between males and females. Some aspects of the sex dimorphism can be attributed to the influence of estrogen on levels of NOS3 (endothelial NOS) and NOS1 (Weiner et al., 1994; Förstermann et al., 1998; Grohé et al., 2004). Given that NOS1 plays a role in stroke, the sex dimorphism of NO regulation would be expected to produce different effects in males and females, and indeed this appears to be the case; while males exhibit lower levels of stroke damage in NOS1 knock-out (KO) mice than wild-type (WT) mice, females have a higher levels of damage in NOS1 knock-out mice than wild-type mice (McCullough et al., 2005). Furthermore, NO antagonists that have a level of selectivity for NOS1, such as 7-NI, are neuroprotective for stroke in males but not in females (McCullough et al., 2005).

Since NOS1 is involved in ischemic damage and synaptic plasticity, but its role in ischemic damage is sex specific, one might predict that the role of NOS1 in synaptic plasticity is also sex specific. We therefore looked at EDP and LTP in the barrel cortex of wild-type and $\alpha$ NOS1 knock-out mice and compared the results across males and females.

\section{Materials and Methods}

Subjects. For the experience-dependent plasticity experiments, we used the following: wild types: male, six deprived ( 105 cells) and seven undeprived (132 cells); female, six deprived (157 cells) and five undeprived (100 cells); $\alpha$ NOS1 knock-outs: male, nine deprived (193 cells) and six undeprived (89 cells); female, five deprived (106 cells) and four undeprived (70 cells). Recordings were made at an average age of 4.4 months (range, 1.7-9.7 months). For the in vitro LTP experiments, we used 19 
A
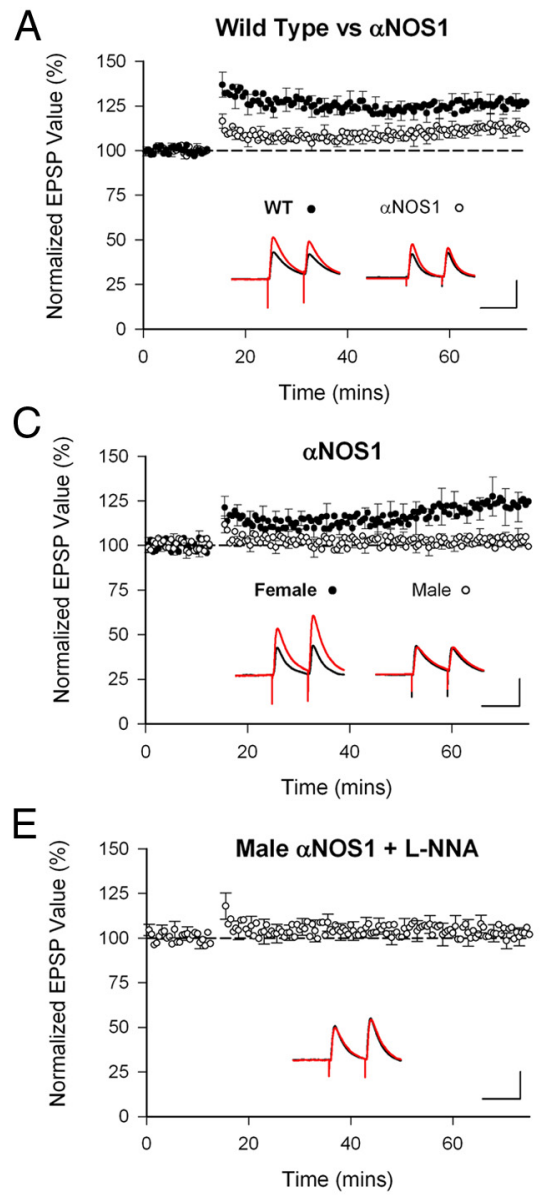

$\mathrm{B}$

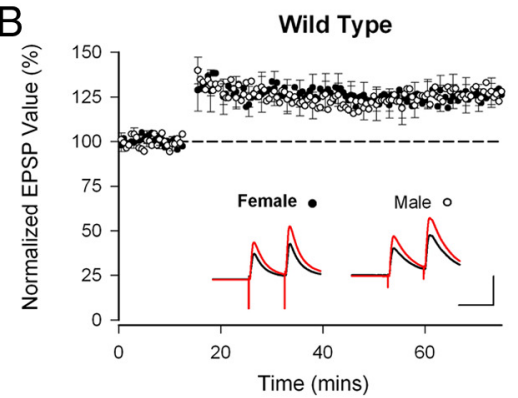

$\mathrm{D}$

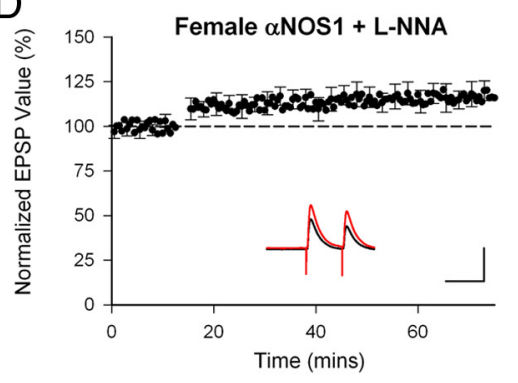

F

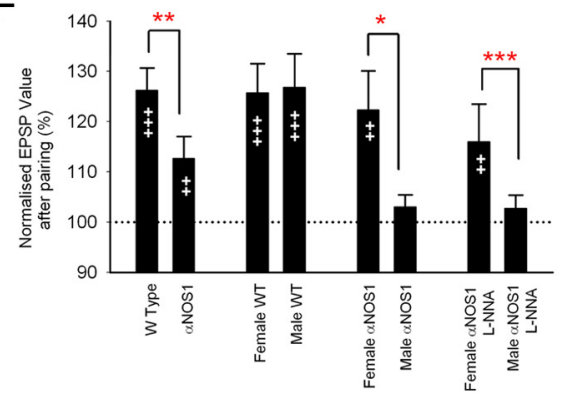

Figure 1. LTP is reduced in $\alpha$ NOS1 knockouts in a sex-specific manner. $\boldsymbol{A}, \mathrm{LTP}$ is reduced in $\alpha$ NOS1 knockouts $(13 \pm 4 \%, n=$ 36) compared with wild types ( $26 \pm 4 \%, n=48$, sexes combined). $\boldsymbol{B}$, Male and female WTs ( $n=24$ for both sexes) showed similar magnitudes of LTP. C, Male $\alpha$ NOS1s show no significant LTP $(n=18)$, while female $\alpha$ NOS1 knockouts show $\operatorname{LTP}(n=18)$. $\boldsymbol{D}, \boldsymbol{E}, \mathrm{L}$-NNA has no effect on levels of LTP in female $\alpha$ NOS1 knockouts $(n=18)(\boldsymbol{D})$ or male $\alpha$ NOS1 knockouts that already lack LTP $(n=18)(\boldsymbol{E}) . \boldsymbol{F}$, Average level of potentiation observed at $60 \mathrm{~min}$, showing within-group significance $\left({ }^{++} p<0.01,{ }^{+++} p<\right.$ 0.001 , paired $t$ test) and comparisons between genotypes or sexes $\left({ }^{*} p<0.05,{ }^{* *} p<0.01,{ }^{* * *} p<0.005\right.$; see Results for details of statistics). Insets show superimposed example EPSPs for baseline (black) and postpairing periods (red) (each trace shows two stimuli at $100 \mathrm{~ms}$ separation). Calibration: $100 \mathrm{~ms}, 5 \mathrm{mV}$.

male and 20 female wild types, and 12 male and 12 female $\alpha$ NOS1 knockouts, aged between 6 and 8 weeks.

The colony of $\alpha$ NOS1 mice was sourced from Jackson Laboratory and outbred four times during a 7 year period to C57BL/6OlaHSD background (Harlan) and were therefore of mixed C57BL/6J and C57BL/6OlaHSD background. Other than for outbreeding, the colony was maintained as heterozygotes. To generate knockouts and wild-type littermates, heterozygote mice were crossed. Males and females were housed separately in cages of two to six mice. Stage of estrus cycle was not determined for female mice.

Whisker deprivation, anesthesia, surgery, and recording. All but the D1 whisker was removed unilaterally for $18 \mathrm{~d}$, followed by $6-10 \mathrm{~d}$ of regrowth before recording. For anesthesia, recording, marking of recording locations, stimulation, and histological methods, see Dachtler et al. (2011b).

Slice preparation for in vitro recordings. Slice preparation, and intracellular and extracellular solutions have been detailed previously (Dachtler et al., 2011b). The L-nitroarginine (L-NNA) concentration was $1 \mathrm{~mm}$ in the intracellular solution. Whole-cell recordings from layer (L) II/III neurons were recorded and LIV stimulated in the adjacent barrel column (average postbreak in potentials were as follows: male wild types, $70 \pm 1 \mathrm{mV}$; female wild types, $68 \pm 1 \mathrm{mV}$; male $\alpha$ NOS1 knockouts, $66 \pm 5 \mathrm{mV}$; and female $\alpha$ NOS1 knockouts, $71 \pm 1 \mathrm{mV}$ ). Recordings were rejected if the series resistance changed by $>20 \%$ during recording. LTP was induced by pairing a presynaptic stimulus with an evoked postsyn- aptic action potential $10 \mathrm{~ms}$ later (50 pairs at 2 $\mathrm{Hz}$; intertrain interval, $30 \mathrm{~s}$ ).

Statistical methods. Spike responses for the D1, principal, and surround whiskers were analyzed as described previously (Dachtler et al., 2011b). Map plasticity was estimated by averaging all LII/III D1 responses within a penetration and assigning each penetration one of the following three bands: blue for $<25$ spikes per 50 stimuli; green for between 25 and 50 spikes per 50 stimuli; and yellow for $>50$ spikes per 50 stimuli. Differences were analyzed using $\chi^{2}$ analysis. All in vivo experiments were performed blind to the effect of sex on plasticity. However, experimenters were not blinded to mouse genotype or gender during the experiments.

EPSP amplitudes were averaged over a 15 min control period. Plasticity was measured by comparing mean amplitudes 50-60 min after the LTP protocol with mean amplitudes from the control period. Datasets were found not to be normally distributed for ANOVA analysis (Shapiro-Wilk test, all groups $p<0.05$ ). Data transforms (square root, log, and inverse) did not adjust distributions to normality, preventing use of an ANOVA. Therefore, we tested each cell to find whether LTP had occurred at the 50-60 min time point using a paired $t$ test and created the consequent binary variable (LTP, no-LTP) to test the probability of LTP using nonparametric statistics (likelihood ratio, Pearson, and Fisher exact probability tests). We also used the Wilcoxon rank order tests to test for differences in the magnitude of LTP between cases. In all cases, $\alpha$ was 0.05 .

\section{Results}

LTP is sex specific in $\alpha$ NOS1 knockouts LTP was significantly reduced in $\alpha$ NOS1 knock-out mice when compared with wild types (Fig. $1 A ; \chi^{2}=6.8, p<0.01$, Wilcoxon rank order test), but potentiation in the $\alpha$ NOS1 KOs was still significantly above baseline levels $\left(\chi^{2}=8.0, p<\right.$ 0.001).

In wild types, the probability of statistically significant LTP $50-60$ min after pairing was $46 \%$ in both males $(n=24)$ and females $(n=24)$. Of those cases that showed potentiation, the average EPSP potentiated by $51 \pm 10 \%$ in male wild-type mice and by $53 \pm 5 \%$ in female wild-type mice compared with baseline values. Across all cases, the average EPSP potentiated by $27 \pm 7 \%$ in male wild-type mice and by $26 \pm 6 \%$ in female wild-type mice (Fig. $1 B$ ).

In the $\alpha$ NOS 1 knock-out mice, the probability of statistically significant LTP was 5\% in males and 33\% in females (both $n=$ 18). Of those cases that showed potentiation, the average EPSP potentiated by $22 \pm 8 \%$ in males (single case) and by $60 \pm 14 \%$ in females. Across all cases, the EPSPs of female $\alpha$ NOS1 knockouts clearly potentiated ( $22 \pm 7 \%$ ), while the average magnitude of male $\alpha$ NOS1 knock-out LTP was just $3 \pm 2 \%$ (Fig. $1 C$ ). There was no effect of sex on the probability $\left(\chi^{2}=0.084, p=0.77\right.$, likelihood ratio test $)$ or magnitude of LTP in wild-type mice $\left(\chi^{2}=0.001\right.$, $p=0.98$, Wilcoxon rank order test). In contrast, there was a significant effect of sex on both the probability $\left(\chi^{2}=4.8, p<\right.$ $0.03)$ and magnitude of LTP in $\alpha$ NOS1 knock-out mice $\left(\chi^{2}=\right.$ $4.5, p<0.05)$. 


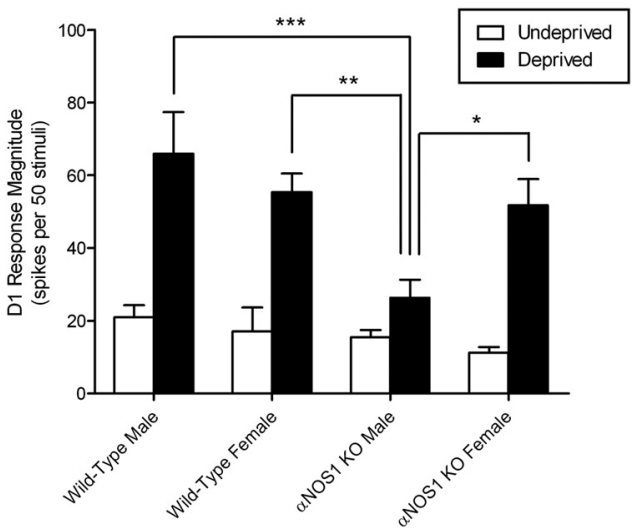

Figure2. Quantification of the LII/III D1 spiking response magnitude in male and female wild-type and $\alpha$ NOS1 knock-out mice following experience-dependent plasticity. The histogram depicts the average D1 response for undeprived controls (white bars) and whisker-deprived mice, whereby all but the D1 whisker had been removed for 18 d, followed by $6-10$ d of regrowth (black bars). Male $\alpha$ NOS1 knock-out mice have significantly less D1 potentiation than male and female wild types and female $\alpha$ NOS1 knockouts (three-way ANOVA followed by test of simple main effects and post hoc $t$ tests, ${ }^{*} p<0.05,{ }^{* *} p<0.01,{ }^{* * *} p<0.0001$; see Materials and Methods for $n$ values).

Previous studies have shown that intracellular administration of the NOS antagonist L-NNA reduces but does not abolish LTP in wild-type mice (Hardingham and Fox, 2006). In contrast, we found no effect of L-NNA on the probability $\left(\chi^{2}=0.08, p=0.77\right)$ or magnitude of LTP in $\alpha$ NOS1 knock-out mice $\left(\chi^{2}=0.04, p=0.84\right)$ (Fig. $1 D, E$ ). However, there was an effect of sex on the probability $\left(\chi^{2}=6.36, p<0.02\right)$ and magnitude of LTP in L-NNA-treated neurons $\left(\chi^{2}=8.1, p<0.005\right)$ due to significant levels of LTP in the female $\alpha$ NOS1 knock-out mice (overall mean EPSP increase $=$ $16.1 \pm 4 \%)$, but not in the males $(2.7 \pm 2 \%)$. These findings confirm the sex difference in the $\alpha$ NOS1 knock-out mice and, in addition, show that the residual LTP in the female $\alpha$ NOS1 knockouts cannot be attributed to NO generated by a different route (e.g., via NOS3).

\section{Experience-dependent plasticity is sex specific in $\alpha$ NOS1 knockouts}

In male and female wild types and female $\alpha$ NOS1 knockouts, a period of single whisker experience produced clear potentiation of the average spiking response to D1 stimulation recorded in the barrel columns surrounding D1 (a 3.2-fold increase in wild-type males; a 3.2-fold increase in wild-type females; a 4.6-fold increase in $\alpha$ NOS1 females; Fig. 2). In contrast, male $\alpha$ NOS1 knockouts increased their spiking response by far less (a 1.7-fold increase; Fig. 2). A three-way ANOVA found a main effect of genotype $\left(F_{(1,40)}=9.48, p=0.004\right)$ and conditioning on spiking response $\left(F_{(1,40)}=57.51, p<0.0001\right)$ but not of $\operatorname{sex}\left(F_{(1,40)}<1\right)$. There was a significant interaction among genotype, sex, and deprivation $\left(F_{(1,40)}=4.17, p=0.048\right)$. No other interactions were significant. Simple main effects analysis showed that there were no significant differences between undeprived male wild-type and undeprived male $\alpha$ NOS1 knock-out mice, undeprived female wild-type and undeprived female $\alpha$ NOS1 knock-out mice, or deprived female wild-type and deprived female $\alpha$ NOS1 knock-out mice (all $\left.F_{(1,40)}<1\right)$. However, there was a significant difference between deprived male wild-type and deprived male $\alpha$ NOS1 knock-out mice $\left(F_{(1,40)}=25.119, p<0.0001\right)$. Independent $t$ tests between male $\alpha$ NOS1 knock-out mice and female wild-type mice, and female $\alpha$ NOS1 knock-out mice also confirmed a significant reduction in potentiation in male $\alpha$ NOS1 knockouts $\left(_{(13)}=3.95, p=0.002\right.$, and $t_{(12)}=2.99, p=0.011$, respectively).
We analyzed map plasticity to test the spatial extent of plasticity in the $\alpha$ NOS 1 males. In all undeprived groups, the spiking responses to D1 whisker stimulation were weak in the D1surrounding barrel columns, and strongest within the D1 barrel column (Fig. 3; note that penetrations are located in congruent positions on the barrel map independent of small differences in barrel size). In wild-type male and female mice, single whisker (D1) experience resulted in robust potentiation of the spiking response to D1 whisker stimulation when recorded in the D1surrounding barrel columns. In male wild types, the proportion of penetrations containing the strongest D1 responses (Fig. 3, green and yellow circles $)$ increased from 40 to $90 \%\left(\chi^{2}=16.53\right.$, $p=0.0003)$, and in female wild types increased from 13 to $84 \%$ $\left(\chi^{2}=19.84, p<0.0001\right)$. This pattern was not observed in the $\alpha$ NOS1 knockouts. While the proportion of penetrations containing strong D1 responses did increase significantly in female $\alpha$ NOS1 knockouts (11 to $81 \% ; \chi^{2}=12.97, p=0.0015$ ), the increase was far smaller (and not statistically significant) in the male $\alpha$ NOS1 knockouts (7 to $43 \% ; \chi^{2}=5.67, p>0.05$ ).

Receptive field size, somatosensory responsivity, and barrel architecture in male and female $\alpha$ NOS1 knock-out mice LII/III cells had normal receptive field sizes in $\alpha$ NOS1 knockouts. Receptive fields were not influenced by genotype or sex (both $\left.F_{(1,18)}<1, p>0.05\right)$, nor interactions between genotype and sex $\left(F_{(1,18)}=2.20, p>0.05\right)$. Whisker response strength was also normal in $\alpha$ NOS1 knockouts. For LII/III, there were no main effects of genotype or sex (both $F_{(1,18)}<1$ ) or genotype by sex $\left(F_{(1,18)}=1.41, p>0.05\right)$ nor interactions (all $\left.F_{(5,90)}<1\right)$, and similarly for LIV there were no main effects of genotype or sex, nor for any interactions (all $F_{(5,85)}<1$ ). For LIV, there was no difference in the proportion of short latency responses $(<10 \mathrm{~ms})$ within the principal barrel between male wild-type mice and $\alpha$ NOS1 knock-out mice $\left(\chi^{2}=2.74, p>0.05\right)$ nor between female wild-type mice and $\alpha$ NOS1 knock-out mice $\left(\chi^{2}=1.31, p>\right.$ $0.05)$. These results indicate that receptive fields and response strengths were normal in $\alpha$ NOS1 knockouts.

Normal barrel patterning was present in $\alpha$ NOS1 knockouts, as shown previously (Finney and Shatz, 1998). Barrel areas for both male and female $\alpha$ NOS1 knock-out mice were slightly smaller (20\%) than their wild-type counterparts (Fig. 4). A repeatedmeasures three-way ANOVA revealed a significant main effect of genotype $\left(F_{(1,18)}=5.35, p=0.033\right)$ but not of sex $\left(F_{(1,18)}<1\right)$. There were no significant interactions between genotype and sex $\left(F_{(1,18)}<1\right)$; barrel area by genotype $\left(F_{(4,72)}=1.17, p>0.05\right)$; barrel area by sex $\left(F_{(4,72)}=1.07, p>0.05\right)$; or barrel area by genotype by $\operatorname{sex}\left(F_{(4,72)}<1\right)$. We also measured the length of the far edges between the D1 and D3 barrels. There was no difference in barrel spacing by genotype $\left(F_{(1,18)}=1.80, p>0.05\right)$ or $\operatorname{sex}\left(F_{(1,18)}<1\right)$, and these factors did not interact with each other $\left(F_{(1,18)}<1\right)$. The $\alpha$ NOS1 knockouts therefore have slightly smaller barrels with normal barrel spacing, but this is not sex specific.

\section{Discussion}

The main finding in this study was that plasticity is reduced in male $\alpha$ NOS1 knock-out mice but present in females. The residual plasticity in female $\alpha$ NOS1 knock-out mice was not NOS dependent, demonstrating that cortical plasticity relies more on NOS in males than in females. The residual experiencedependent plasticity in the male and female $\alpha$ NOS1 knockouts is likely to be via GluR1 (Dachtler et al., 2011b).

The size of the deficit was greater for LTP than EDP. This may be because the LIV-LII/III pathway tested in the LTP studies is 

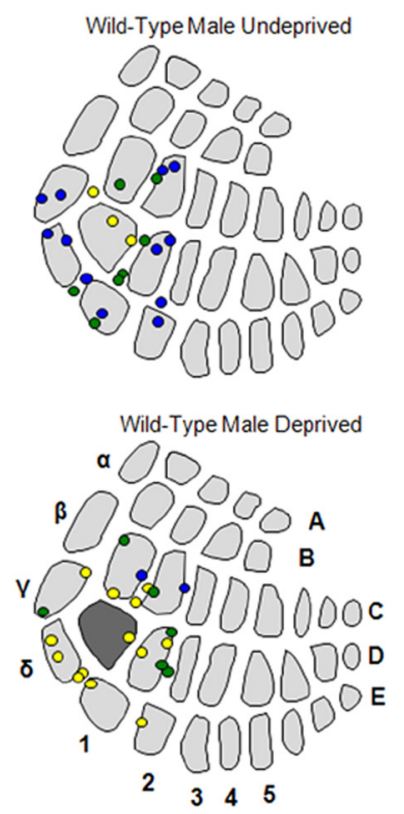
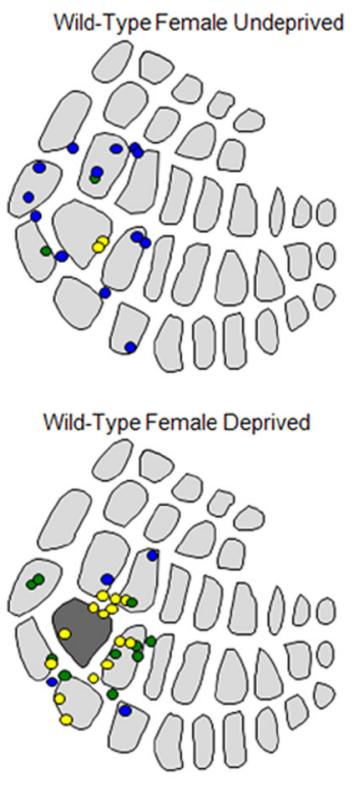
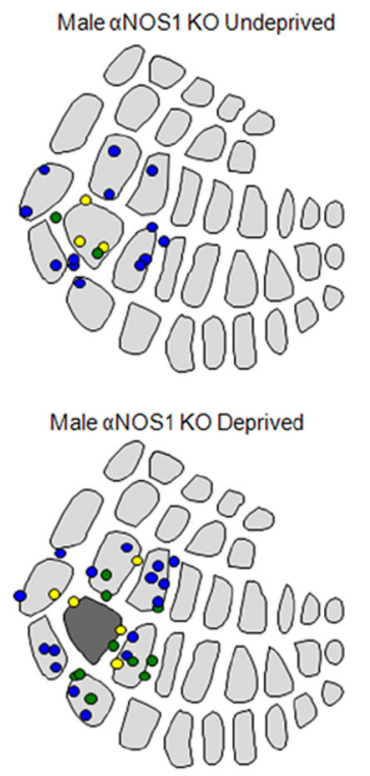



Female $\alpha$ NOS1 KO Deprived

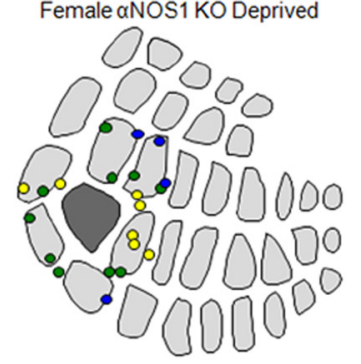

Figure 3. Experience-dependent plasticity of male and female wild-type and $\alpha$ NOS1 knock-out mice in the barrel cortex. The spatial domain of the D1 spared whisker response expands and invades the surrounding barrel columns in deprived male and female wild-type mice and female $\alpha$ NOS1 knock-out mice, but not in male $\alpha$ NOS1 knock-out mice. Each penetration represents the average LII/III response, where at least three cells were recorded per penetration. The response level is color coded, with yellow being the strongest (response $>50$ spikes per 50 stimuli), green being the mid-range (response $<50$ but response $>25$ spikes per 50 stimuli), and blue being the weakest (response $<25$ spikes per 50 stimuli). Top row, D1 response domains for undeprived mice. Note that the strongest responses are normally confined to the D1 barrel. Bottom row, D1 domains for mice with all but the D1 whisker deprived for $18 \mathrm{~d}$. The D1 barrel is shaded dark gray. Note that in most cases the stronger responses expand out of the D1 barrel column into surrounding barrel columns.
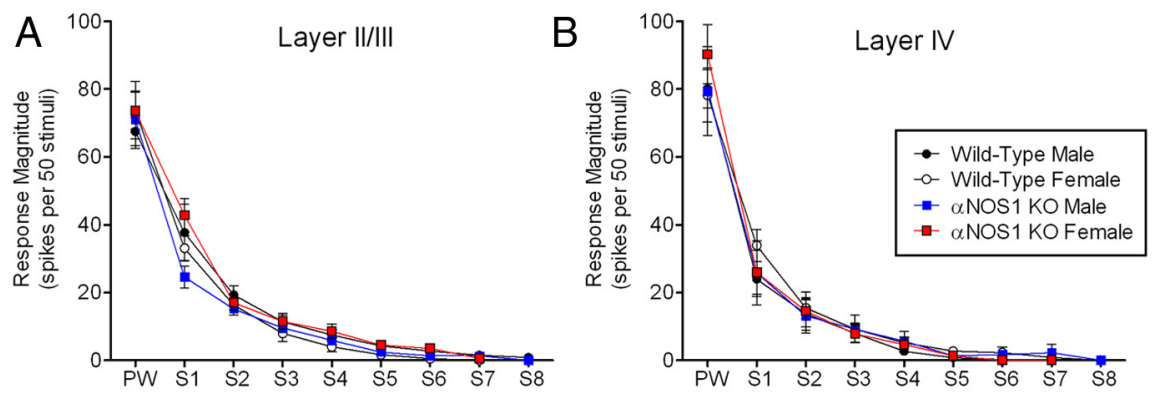

C

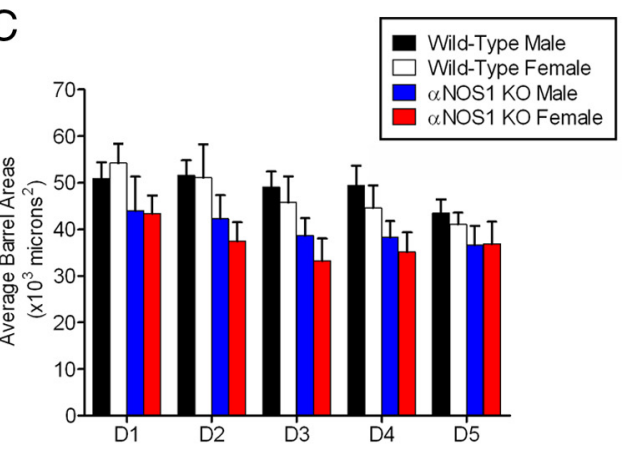

D

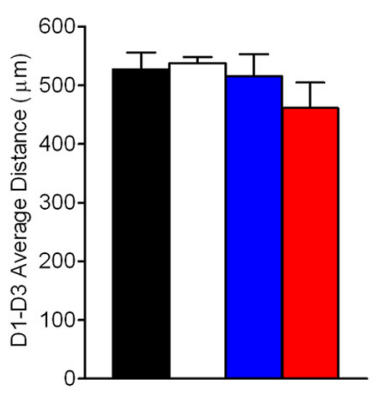

Figure 4. The development of barrel field structure and receptive field size in male and female wild-type and $\alpha$ NOS1 knock-out mice. Receptive field structure and responsiveness are similar between wild-type and $\alpha \mathrm{NOS} 1$ knock-out mice. $\boldsymbol{A}, \boldsymbol{B}$, The responses to stimulation of the anatomically defined principal whisker (PW) and all surrounding whiskers (S) ranked from greatest to smallest $(S 1-S 8)$ are shown for LII/III $(\boldsymbol{A})$ and LIV $(\boldsymbol{B})$. There were no main effects of genotype, sex, or interactions between the two for either layer (all $p>0.05$ ). Tissue containing the barrel cortex were sectioned and reacted for cytochrome oxidase to visualize the LIV barrel field. C, Individual D-row barrel areas were significantly smaller in $\alpha$ NOS1 knock-out mice compared with wild types (main effect of genotype, $p=0.033$ ), although there were no significant differences between the sexes. $\boldsymbol{D}$, There were no significant differences between genotype or sex for the barrel spacing, measured between the center of the far edge of $D 1$ to the center of the far edge of D3. $\boldsymbol{A}-\boldsymbol{C}$ were analyzed by repeated-measures two-way ANOVA, and $\boldsymbol{D}$ by a two-way ANOVA (see Materials and Methods for $n$ values).

more reliant on $\alpha$ NOS1 than other pathways recruited during in vivo plasticity. Alternatively, the greater deficit in LTP may be attributable to the shorter duration of plasticity induction of LTP compared with EDP. The female mice in these studies go through several (4 d) estrus cycles during the $26 \mathrm{~d}$ deprivation/regrowth period. Since estradiol only causes an increase in NMDA receptors and spine density in females (Romeo et al., 2005), spine density may alter in the female mice several times during the deprivation period, which could provide an increased substrate for plasticity.

NO has several routes by which it can affect plasticity. $\mathrm{NO}$ acts via guanyl cyclase (GC), which is vital for LTP in the visual cortex (Haghikia et al., 2007). GC in turn affects GluR1 trafficking (Serulle et al., 2007) and presynaptic function (Arancio et al., 2001). NOS1 is also known to affect CRE-mediated gene expression (Peunova and Enikolopov, 1993), and in the barrel cortex NO affects gene expression via ERK (Gallo and Iadecola, 2011). As CREB is known to be involved in adult barrel cortex plasticity (Glazewski et al., 1999), this represents a third possible route of action.

While most of our findings relate to sex differences, we did find one difference between genotypes. The crosssectional area of the barrels defined by cytochrome oxidase staining was 
slightly smaller in the male and female $\alpha$ NOS1 knock-out mice. In agreement with earlier studies, the pattern of the barrels was unaffected in $\alpha$ NOS1 knock-out mice (Finney and Shatz, 1998). The developmental difference cannot explain why males showed reduced EDP and a lack of LTP because the female $\alpha$ NOS1 knockouts had the same barrel size as the males and yet showed normal levels of plasticity.

Our studies raise the question of whether synaptic plasticity mechanisms are generally different between sexes. A recent review on the topic identified nine different plasticity factors that differ with sex (Mizuno and Giese, 2010). In addition, contextual fear conditioning is GluR1 dependent in male mice but not in female mice (Dachtler et al., 2011a). There is considerable evidence that cognition and plasticity also differ with sex in wild-type animals. In a meta-analysis of sex differences, it was shown that male rats perform better in spatial navigation tasks (Jonasson, 2005). Similarly, sex differences in LTP were found in the wild-type hippocampus. CA1 LTP is identical in males and females if tested with a sustained $100 \mathrm{~Hz}$ tetanus, but greater in males if intermittent $100 \mathrm{~Hz}$ short bursts of four pulses are used (Yang et al., 2004). The latter may be related to NO-dependent LTP because it has been shown that intermittent bursts (typical of theta activity) produce more postsynaptic spikes than a sustained $100 \mathrm{~Hz}$ tetanus (Phillips et al., 2008). Since postsynaptic spikes are necessary for NO-dependent LTP in the hippocampus (Phillips et al., 2008), the greater efficacy of intermittent short bursts in the males than the females could be indicative of greater NOdependent LTP in the males. Finally, the fact that antagonists with some selectivity for NOS1 can only reduce the ischemic damage caused by stroke in male wild-type mice again argues for differences in NO signaling dependency between wild-type males and females (McCullough et al., 2005).

Is it possible that the greater reliance on NOS1 for plasticity in male mice is directly related to the neuroprotective effect of NOS1 inhibition or knockout in males but not in females (Huang et al., 1994; McCullough et al., 2005)? It has been argued that NOS1 is not capable of generating sufficient NO to produce direct ischemic damage itself, for example by inhibiting cytochrome-c, which would require micromolar concentrations of NO (Keynes and Garthwaite, 2004). However, it remains possible that NOS1 is activated during ischemia, which then causes potentiation of excitatory transmission and thereby increases levels of excitotoxic damage further in a positive feedback loop. Our present findings would predict that any such potentiation-exacerbated ischemia would be reduced by NOS1 inhibition in males but not in females. We would also predict that NOS1 inhibition would be counterproductive during recovery and rehabilitation from stroke, as plasticity processes at excitatory synapses would also be involved in repair and formation of new neural circuits

\section{References}

Arancio O, Antonova I, Gambaryan S, Lohmann SM, Wood JS, Lawrence DS, Hawkins RD (2001) Presynaptic role of cGMP-dependent protein kinase during long-lasting potentiation. J Neurosci 21:143-149. Medline

Bano D, Nicotera P (2007) Ca2 + signals and neuronal death in brain ischemia. Stroke 38:674-676. CrossRef Medline

Bliss TV, Collingridge GL (1993) A synaptic model of memory: long-term potentiation in the hippocampus. Nature 361:31-39. CrossRef Medline

Cao J, Viholainen JI, Dart C, Warwick HK, Leyland ML, Courtney MJ (2005) The PSD95-nNOS interface: a target for inhibition of excitotoxic p38 stress-activated protein kinase activation and cell death. J Cell Biol 168: 117-126. CrossRef Medline

Constantine-Paton M, Cline HT, Debski E (1990) Patterned activity, synaptic convergence, and the NMDA receptor in developing visual pathways. Annu Rev Neurosci 13:129-154. CrossRef Medline

Dachtler J, Fox KD, Good MA (2011a) Gender specific requirement of GluR1 receptors in contextual conditioning but not spatial learning. Neurobiol Learn Mem 96:461-467. CrossRef Medline

Dachtler J, Hardingham NR, Glazewski S, Wright NF, Blain EJ, Fox K (2011b) Experience-dependent plasticity acts via GluR1 and a novel neuronal nitric oxide synthase-dependent synaptic mechanism in adult cortex. J Neurosci 31:11220-11230. CrossRef Medline

Dawson VL, Kizushi VM, Huang PL, Snyder SH, Dawson TM (1996) Resistance to neurotoxicity in cortical cultures from neuronal nitric oxide synthase-deficient mice. J Neurosci 16:2479-2487. Medline

Finney EM, Shatz CJ (1998) Establishment of patterned thalamocortical connections does not require nitric oxide synthase. J Neurosci 18: 8826-8838. Medline

Förstermann U, Boissel JP, Kleinert H (1998) Expressional control of the "constitutive" isoforms of nitric oxide synthase (NOS I and NOS III). FASEB J 12:773-790. Medline

Gallo EF, Iadecola C (2011) Neuronal nitric oxide contributes to neuroplasticity-associated protein expression through cGMP, protein kinase G, and extracellular signal-regulated kinase. J Neurosci 31:69476955. CrossRef Medline

Glazewski S, Barth AL, Wallace H, McKenna M, Silva A, Fox K (1999) Impaired experience-dependent plasticity in barrel cortex of mice lacking the alpha and delta isoforms of CREB. Cereb Cortex 9:249-256. CrossRef Medline

Grohé C, Kann S, Fink L, Djoufack PC, Paehr M, van Eickels M, Vetter H, Meyer R, Fink KB (2004) 17 Beta-estradiol regulates nNOS and eNOS activity in the hippocampus. Neuroreport 15:89-93. CrossRef Medline

Haghikia A, Mergia E, Friebe A, Eysel UT, Koesling D, Mittmann T (2007) Long-term potentiation in the visual cortex requires both nitric oxide receptor guanylyl cyclases. J Neurosci 27:818-823. CrossRef Medline

Hajimohammadreza I, Probert AW, Coughenour LL, Borosky SA, Marcoux FW, Boxer PA, Wang KK (1995) A specific inhibitor of calcium/ calmodulin-dependent protein kinase-II provides neuroprotection against NMDA- and hypoxia/hypoglycemia-induced cell death. J Neurosci 15:4093-4101. Medline

Hardingham N, Fox K (2006) The role of nitric oxide and GluR1 in presynaptic and postsynaptic components of neocortical potentiation. J Neurosci 26:7395-7404. CrossRef Medline

Herron CE, Lester RA, Coan EJ, Collingridge GL (1986) Frequencydependent involvement of NMDA receptors in the hippocampus: a novel synaptic mechanism. Nature 322:265-268. CrossRef Medline

Huang Z, Huang PL, Panahian N, Dalkara T, Fishman MC, Moskowitz MA (1994) Effects of cerebral ischemia in mice deficient in neuronal nitric oxide synthase. Science 265:1883-1885. CrossRef Medline

Jonasson Z (2005) Meta-analysis of sex differences in rodent models of learning and memory: a review of behavioral and biological data. Neurosci Biobehav Rev 28:811-825. CrossRef Medline

Keynes RG, Garthwaite J (2004) Nitric oxide and its role in ischaemic brain injury. Curr Mol Med 4:179-191. CrossRef Medline

Lynch G, Larson J, Kelso S, Barrionuevo G, Schottler F (1983) Intracellular injections of EGTA block induction of hippocampal long-term potentiation. Nature 305:719-721. CrossRef Medline

Malinow R, Madison DV, Tsien RW (1988) Persistent protein kinase activity underlying long-term potentiation. Nature 335:820-824. CrossRef Medline

Manso H, Krug T, Sobral J, Albergaria I, Gaspar G, Ferro JM, Oliveira SA, Vicente AM (2012) Variants within the nitric oxide synthase 1 gene are associated with stroke susceptibility. Atherosclerosis 220:443-448. CrossRef Medline

McCullough LD, Zeng Z, Blizzard KK, Debchoudhury I, Hurn PD (2005) Ischemic nitric oxide and poly (ADP-ribose) polymerase-1 in cerebral ischemia: male toxicity, female protection. J Cereb Blood Flow Metab 25:502-512. CrossRef Medline

Mizuno K, Giese KP (2010) Towards a molecular understanding of sex differences in memory formation. Trends Neurosci 33:285-291. CrossRef Medline

Nanri K, Montecot C, Springhetti V, Seylaz J, Pinard E (1998) The selective 
inhibitor of neuronal nitric oxide synthase, 7-nitroindazole, reduces the delayed neuronal damage due to forebrain ischemia in rats. Stroke 29: 1248-1253, 1998; discussion 1253-1244. CrossRef Medline

Olney J, Price M, Salles KS, Labruyere J, Frierdich G (1987) MK-801 powerfully protects against $\mathrm{N}$-methyl aspartate neurotoxicity. Eur J Pharmacol 141:357-361. CrossRef Medline

Peunova N, Enikolopov G (1993) Amplification of calcium-induced gene transcription by nitric oxide in neuronal cells. Nature 364:450-453. CrossRef Medline

Phillips KG, Hardingham NR, Fox K (2008) Postsynaptic action potentials are required for nitric-oxide-dependent long-term potentiation in CA1 neurons of adult GluR1 knock-out and wild-type mice. J Neurosci 28: 14031-14041. CrossRef Medline

Romeo RD, McCarthy JB, Wang A, Milner TA, McEwen BS (2005) Sex differences in hippocampal estradiol-induced N-methyl-D-aspartic acid binding and ultrastructural localization of estrogen receptor-alpha. Neuroendocrinology 81:391-399. CrossRef Medline

Schuman EM, Madison DV (1991) A requirement for the intercellular messenger nitric oxide in long-term potentiation. Science 254: 1503-1506. CrossRef Medline

Serulle Y, Zhang S, Ninan I, Puzzo D, McCarthy M, Khatri L, Arancio O, Ziff EB (2007) A GluR1-cGKII interaction regulates AMPA receptor trafficking. Neuron 56:670-688. CrossRef Medline

Weiner CP, Lizasoain I, Baylis SA, Knowles RG, Charles IG, Moncada S (1994) Induction of calcium-dependent nitric oxide synthases by sex hormones. Proc Natl Acad Sci U S A 91:5212-5216. CrossRef Medline

Yang DW, Pan B, Han TZ, Xie W (2004) Sexual dimorphism in the induction of LTP: critical role of tetanizing stimulation. Life Sci 75: 119-127. CrossRef Medline 